ship with the pubes. It had been in marked retrocession. The case demonstrated the ease of access to these ligaments through the posterior vaginal vault.

The writer would draw the following conclusions:

1. That retrocession has been too often overlooked in the explanation of pelvic pain.

2. That the condition of the utero-sacral ligaments must be taken into consideration in the treatment of anteflexion.

3. That this condition can easily be relieved by operative measures, if local treatment does not succeed.

\title{
AN INVESTIGATION INTO THE SO-CALLED LYMPHOID NODULES OF THE LIVER IN ABDOMINAL TYPHUS.
}

\author{
By Walter Reed, M.D., \\ SURGEON U. S. ARMY. \\ (From the Pathological Laboratory of the Johns Hopkins University.)
}

THe pathological changes met with in the liver of those who have died of typhus abdominalis have, for a long time, attracted the attention of investigators. Perhaps to Friedreich ${ }^{1}$ should be given the credit for the discovery of certain circumscribed nodular formations which he described as occurring in the liver of a girl, twenty-one years of age, who had died of typhoid fever. He found, in the neighborhood of the coarser bands of stroma, collections of cells which could not be seen with the naked eye, but which, viewed microscopically, consisted of round and partly irregular cells imbedded in the connective tissue of the organ. While this description is not complete, since Friedreich only saw these collections of cells in the interstitial connective tissue, yet it is, we think, sufficiently accurate to justify the belief that he saw what E. Wagner, ${ }^{2}$ three years later, so minutely described. The latter's classical description of the hepatic lesions seen by him in five patients who had died of typhus abdominalis has scarcely been added to up to the present time. As regards his first case, Wagner describes the liver as of normal size and anæmic in appearance, somewhat softened, and with the outlines of the lobules obscure. He saw over all portions of the organ quite numerous, small areas, which were just on the limit of visibility, of a gray color, and fairly solid in character. This refers to the naked-eye appearance. Upon microscopical examination these spots were found to be round, oblong, sometimes irregular, serrated and

\footnotetext{
1 Ein neuer Fall pon Leukamie, Virchow's Archiv, 1857, Band xii. S. 53.

2 Beiträge zur pathologischen Anatomie der Leber bei Abdominal Typhus, Arebiv d. Heilkunde, 1860 , Band i. $\$ .322$.
} 


\section{REED : LYMPHOID NODULES OF THE LIVER.}

biscuit-shaped, the majority of them occupying the actual parenchyma of the organ, and replacing the hepatic cells. Now and then they invaded the interlobular connective tissue. They consisted of closely lying groups of small, round and oval refractive nuclei ; in some places, on the periphery of the area masses of these nuclei, of pointed shape, projected into the surrounding liver tissue. Wagner was of the opinion that these nuclei were derived partly from the cells of the interacinous connective tissue, and that in part they had their origin within the lobules. He was unable to completely demonstrate the manner of production last mentioned, but thought that these nuclei owed their origin to the nuclei of the liver cells. In a second case of typhoid fever, Wagner ${ }^{1}$ saw these fine, barely visible, sharply circumscribed grayish specks over all parts of the cut surface of the liver. As a rule they were immediately on the periphery of the small portal veins, and consisted of albuminoid molecules between which small round refractive nuclei were quite regularly distributed, and in contrast with the central part of the area, which appeared to consist of irregular particles, the periphery was largely made up of round nuclei.

The third case investigated by Wagner ${ }^{2}$ is of interest in connection with our own investigations. The patient had recovered from an attack of typhoid fever, but had died from some other disease two and a half months later. The characteristic nodules were not found in this case, and the inference is drawn that they had been present, but had entirely disappeared, their place being probably taken by a new formation of liver cells.

Hoffmann, ${ }^{3}$ referring to the previous investigations of Wagner, states that he has also found in a considerable number of cases of typhoid fever small grayish nodules in the liver, and says that in most cases it requires close inspection in order to see them with the naked eye; that in some cases they are quite distinct, and on the cut surface, appear as flat elevations ; microscopically they appear as round conglomerations of small round cells and nuclei, resembling the lymphoid nodules found in the peritoneum. He states that their location is, in most cases, within the lobules, and close to one of the small portal spaces. $\mathrm{He}$ found, almost without exception, a diffuse infiltration of cells which followed the ramifications of the portal vein. He regards them as lymphoid cells which have wandered in from the portal vein. Of 250 cases examined, he observed these nodules in the liver in 38 , and in 14 of the 38 the nodules could be seen with the naked eye.

\footnotetext{
1 Die Körnchenbildung in đer Leber, Arcb d. Heilkunde, 1861. Band ì. S. 103-114.

2 Beitrige zur Pathologie und patbologisehen Anatomie der Leber, Dentscbes Archiv für klin. Med., 1883-4, Band xxxiv. S. 520-537.

${ }^{3}$ Untersuchungen tiber die pathologisch-anatomischen Veriunderungen der Organe beim abdominal Typbus, Leipzig, 1869, S. 221-222.
} 
Orth $^{1}$ states that the microscopic gray nodules found in the liver of typhus abdominalis are of the same formation as those seen in leukæmia and lymph adenomata.

Fraenkel and Simmonds, ${ }^{2}$ while studying the hepatic changes in abdominal typhus, always found lesions which they considered to be intimately connected with the disease, viz., small cell infiltration of the connective tissue, and those peculiar formations generally known as lymphomata. They describe two forms which they think are deserving of the latter term: First, those areas which consist of closely packed small, round cells, amongst which may be recognized, here and there, liver cells. Secondly, those in which the round cell accumulation is less close, and which appear to consist largely of the remains of poorly staining liver cells. There are also small, circumscribed areas of liver tissue, in which the protoplasm and nuclei of the cells only stain imperfectly, or not at all, and which do not deserve to be designated as lymphomata. They are inclined to consider this latter form as one of coagulation necrosis. They are further of the opinion that in the beginning the change is one of circumscribed degeneration, and that later there takes place an accumulation of round cells within the necrotic area. They regard as improbable any direct connection between the presence of typhus bacilli and these formations, although they once found a clump of the bacilli within an affected spot.

Handford ${ }^{3}$ states that in all fatal cases of typhoid fever examined by him there were found definite changes in the liver, in the form of parenchymatous and interstitial changes. The most characteristic change, though not constant, is the presence of small, round areas that stain imperfectly, that are crowded more or less thickly with leucocytes, and surrounded by a dense ring of cellular infiltration. The liver cells in the patches show cloudy swelling or more advanced degeneration. In more advanced stages the liver cells cannot be distinguished at all, and mingled with the leucocytes are irregularly shaped and spindle cells. In fact the tissue resembles an early stage of cicatricial tissue. In a third variety the patches cannot be distinguished from miliary abscesses. Handford regards the last as a septic hepatitis, due to absorption of septic particles from the intestine, while the former are due to capillary embolism. He is not satisfied that any specific bacillus is the cause of these lesions.

Siredey ${ }^{4}$ states that during the course of the second week, and sometimes during the third week of typhoid fever, the microscopical appear-

1 Lehrbuch der speciellen pathologischen Anatomie, 1887, Band i, \$., 954.

2 Die aetiologische Bedeutung des Typhus Bacillus, Leipzig, 1886.

3 "Hepatitis in Enteric Fever." Transactions of the Pathological Society of London, 1889, pp. 129-132.

4 Contribution a l'études des alterations du foie dans les maladies infectieuses, Rev. de Méd، vi., Paris, 1886. 
ance found on section of the liver is so peculiar and distinct tbat one can, in the majority of cases from these appearances alone, make a diagnosis of that disease. He describes the lesions as being scattered in various parts of the hepatic substance, and says that their form, location, and size are extremely variable; that while ordinarily round, they are sometimes ovoid or even star-shaped. They are oftener met with at the centre and in the midst of the lobule than at the periphery. He remarks that they offer the greatest analogy in their general shape to tuberculous nodules; but they do not present the distinct layers found in the latter, nor does one see giant cells, nor epithelioid cells. He states that he has never seen any tendency to caseation in these nodules; that they never include hepatic cells, and that the cells composing tbem are but little, if at all altered. He further says that although these nodules are perhaps special to typhoid fever, and that when once encountered in the liver the diagnosis is probable, yet there are other infectious maladies characterized by tbe migration of lymphoid cells into the liver, and that tbese can under certain circumstances present themselves as nodular conglomerations. He expresses the probable opinion that after convalescence the liver parencbyma is fully restored to its former integrity without any lesion being left bebind.

Legry ${ }^{1}$ has contributed an interesting monograph to this subject. In addition to a study of the lesions found in the human liver in typhoid fever, he has injected pure cultures of typhoid bacilli into tbe mesenteric vein of rabbits, and afterward investigated the change, if any, found in the liver. The fact is worth mentioning in this connection, that our experiments on rabbits, carried out in much the same manner as Legry had done, were completed prior to our acquaintance with his monograph, and that while his experiments were attended with negative results as far as finding any changes in the rabbit's liver are concerned, our own experiments were followed by characteristic lesions, as will be later shown. He gives much the same general description as to the location of tbese nodules as Siredey had already done; but does not agree with him that they consist of lymphoid cells. He supports the conclusion that these nodules, which are found most often along the portal spaces, are always formed of nuclei, generally abundant, surrounded by a granular substance, which latter appears to result from the degenerated protoplasm of liver cells. He gives no definite opinion as to the source of these nuclei, but thinks that the nodules have a bacterial origin. $\mathrm{He}$ never found tbe bacilli within the nodules, but has found upon section, six times in eleven cases, characteristic clumps of typhoid bacilli. His experiments upon rabbits (two cases) gave no definite results.

It will thus be seen that each of the writers to whose investigations

\footnotetext{
i Contribution a l'étude du foie dans le fievre typhoide. Paris, 1890.
} 
we have referred describe, with more or less particularity, certain nodular formations found in the liver of those who have died of typhoid fever.

Our own investigations have been carried on in the Pathological Laboratory of the Johns Hopkins University, and have consisted in a careful study, microscopically, of the livers of five patients who had died of typhoid fever in the wards of the Johns Hopkins Hospital. We have also injected pure cultures of typhoid bacilli into the mesenteric vein of rabbits, and afterward studied the lesions found in their livers.

Before we proceed to a description of the microscopic appearances we wish to state that although it is not always possible to distinguish with the naked eye the nodular formations which Wagner discovered microscopically, yet a patient search of the cut surface of the organ will generally be rewarded by finding here and there very small, roundish, grayish white specks within the lobules; sometimes they are quite abundant and easily to be seen-again just on the limits of visibility, and with difficulty found.

Microscopic Appearance of the Liver. In two of the cases studied by us frozen sections of the fresh liver were made. In addition to the well-marked fatty infiltration of the cells, the latter being generally filled with large fat drops, there were also to be seen within the lobules well-defined areas which contained many fatty granular cells situated in the midst of a coarse granular material. Within these areas there were also to be observed many irregular-shaped nuclei.

For the further study of the inicroscopic appearances the following method was used, viz.: Fresh portions of the liver were hardened in 95 per cent. alcohol, and afterward imbedded in paraffin or celloidin. Sections of these were then stained with Löffler's methylene-blue solution for ten to thirty minutes; then transferred to $\frac{1}{4}$ per cent. aqueous solution of eosin, where they remained from fifteen to forty-five seconds; next decolorized and dehydrated in absolute alcohol, cleared in oil of cloves or bergamot, and mounted in Canada balsam.

If, as is sometimes the case, we are unable to see with the naked eye the small whitish areas on the cut surface of the liver of typhoid fever, when we come to the microscopical examination of the organ we no longer experience any difficulty in finding them. If one has succeeded in obtaining a properly stained section a most striking picture is presented to the eye when examined with the low power, and that feature which will most quickly fix the attention is the presence of bright, sharply defined eosin-stained areas of various shapes and sizes, which are to be seen scattered plentifully throughout the section, and in almost every field. Sometimes these areas are almost perfectly round, more often oval, and generally irregular in outline. The sizes of these foci are as variable as their shapes, embracing now only a few liver cells, again involving as much as one-half or even the whole of a lobule. Their 
relative position is also very variable; sometimes we find them near the portal spaces-again in the midst of the lobule, and quite as often situated near the central vein. We have several tines observed an area occupying the entire periphery of the central vein. It cannot be said, we think, that these areas stand in closer relation to the portal vein than to the hepatic spaces. If the section has been well stained there should never be any difficulty in picking out even the smallest necroses, since the contrast bctween the healthy cells, which are stained with methylene-blue, and the necrotic eosin-stained cells is always well marked.

The appearance of these areas is variable. Sometimes we see a spot involving as much as one-fourth of a lobule in which the liver-cells have

FiG. 1.

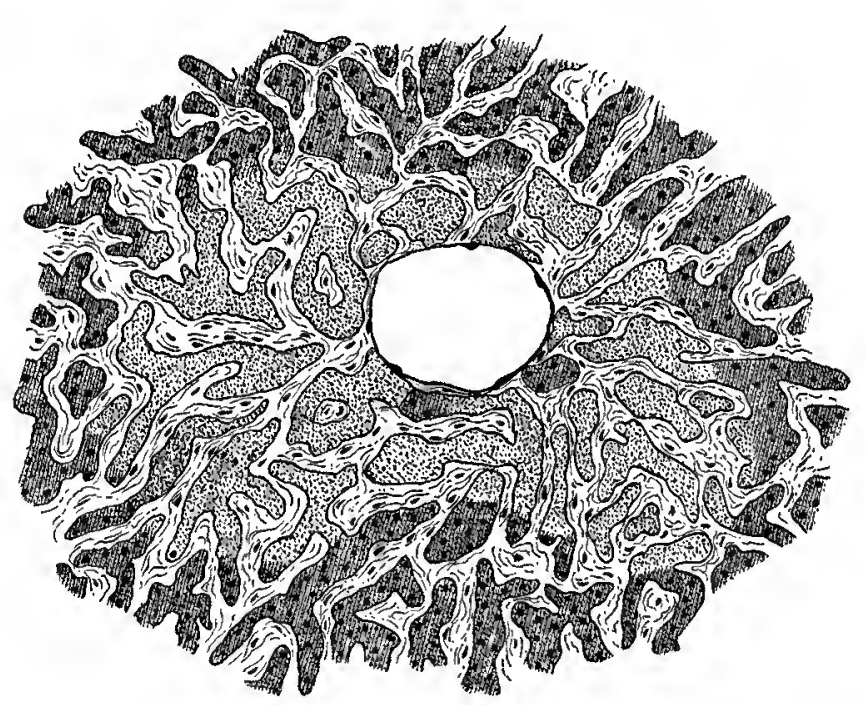

A necrotic aren of the human liver of typhoid fever. The area of necrosis entirely surrounds the central vein of the lobule; the cells have lost their nuclei, but still retain their continuity with the healthy cells. Drawn with camera lucida, Bausch \& Lomb 1/6 objective, Leitz ocular No. 4. Reduced $1 / 4$.

apparently died en masse, but continue to retain their shape perfectly; even the demarcation between the individual cells can still be plainly made out. The beam-work of the cells will not be at all broken, but will be seen to be continuous with that of the surrounding healthy cells (Fig. 1). The capillaries of such an area will be found to be unaltered, or perhaps slightly dilated. Continuing the examination with the low power, we will most often fail to discover any nuclei whatever within the finely granular eosin-staining cells; and even with a high amplifica- 
tion may only find within these cells minute particles of nuclear detritus. We have seen several such areas as the one now being described, in which there appeared no increase whatever of the cells within the capillaries situated between the rows of necrotic cells. In other instances we have found the capillaries to contain a considerable number of polynuclear leucocytes. Sometimes we have seen a marked increase of polynuclear cells within the capillaries, near the centre of the area; again, the largest number will be found about the periphery of the necrosis. We are inclined to regard the areas just described as probably the earliest form of the local parenchymatous degeneration. These are the areas which Frankel and Simmonds consider to have undergone coagulation necrosis, and which, in their opinion, do not deserve to be designated as lymphomata.

Far more frequently one will see areas wherein the liver cells no longer preserve the regularity of their framework, but have become dis-

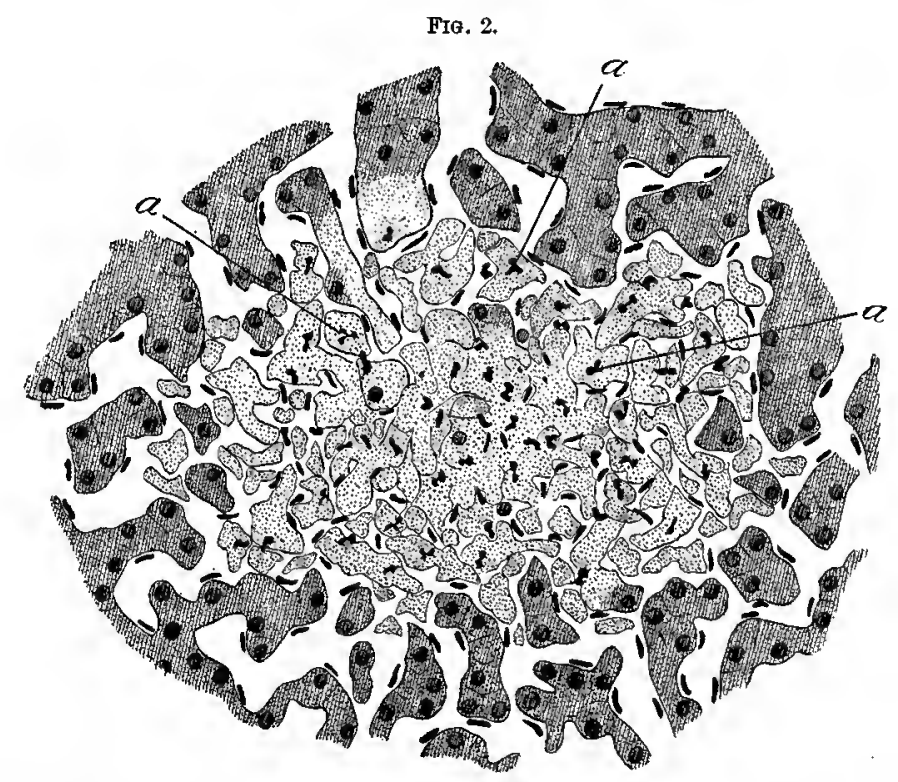

Necrosis of human liver in typhoid fever. a. Polynuclear leucocytes within the dead hepatic cells, which latter have in large part lost their shape. Camera lucida drawing, Leitz 1/12 immersion, No. 3 ocular. Reduced $1 / 4$.

placed and have lost their shape. Some of these cells may still show pale and swollen nuclei, but the majority will have entirely lost their nuclei, and in their stead there will be discovered within many of the necrotic cells one or several polynuclear leucocytes (Fig. 2). The presence of the irregular and club-shaped nuclei within the necrotic cells of the area is one of the most striking and important features to be 
observed. Although certain areas may show only a small number of such nuclei, as a rule they are found in great abundance. We have never, however, observed such an abundance of polynuclear leucocytes within a necrosis in the human liver as to give the picture of a miliary abscess such as is described by Hanford. Sometimes we find included within such an area, and completely surrounded by the necrotic cells, from one to a dozen or more apparently healthy liver cells which still preserve their nuclei, and which do not stain with eosin. These cells, as a rule, contain many fat drops, but in this respect do not differ much from the cells throughout the section.

In addition to the two varieties of areas described we will find others which have undergone yet further changes. Here the hepatic cells have

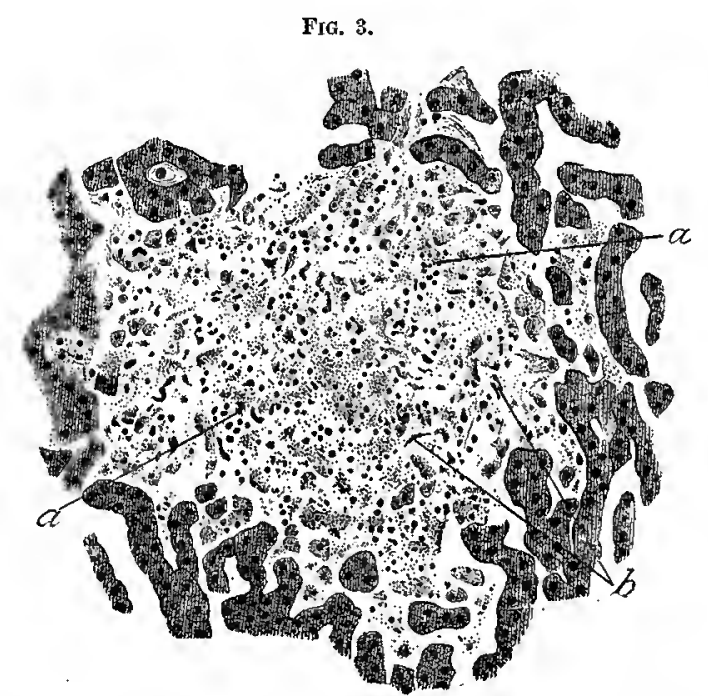

Later stage or necrotic area of human liver in typhoid fever. The cells have entirely lost their shape; many small round nuclei within area $(a)$, and here and there $a$ few spindle cells (b). Camera lucida drawing, Bausch \& Lomb 1/6 objective, Leitz ocular No. 3. Reduced 1/4.

quite disappeared, and are replaced by numerous small, round, deeplystaining nuclei, which crowd the area in all parts, intermixed with fewer oval, spindle-shaped nuclei (Fig. 3). In other words, the appearance is that of young connective-tissue, as mentioned by Hanford.

Besides these larger areas of necrosis, we wish to invite attention to the smaller necroses which are found in the liver. We here refer to the necrosis of individual liver-cells. We have found these smaller necroses in each of the cases examined. In one case they were a prominent feature of the examination (Fig. 4). We find scattered here and there amongst the healthy cells of the lobule one or more cells whose proto- 
plasm stains brightly with eosin, and whose nuclei have, as a rule, entirely disappeared. We will generally observe that such necrotic cells contain within them several irregular-shaped nuclei, which plainly mark the entrance of polynuclear leucocytes into them.

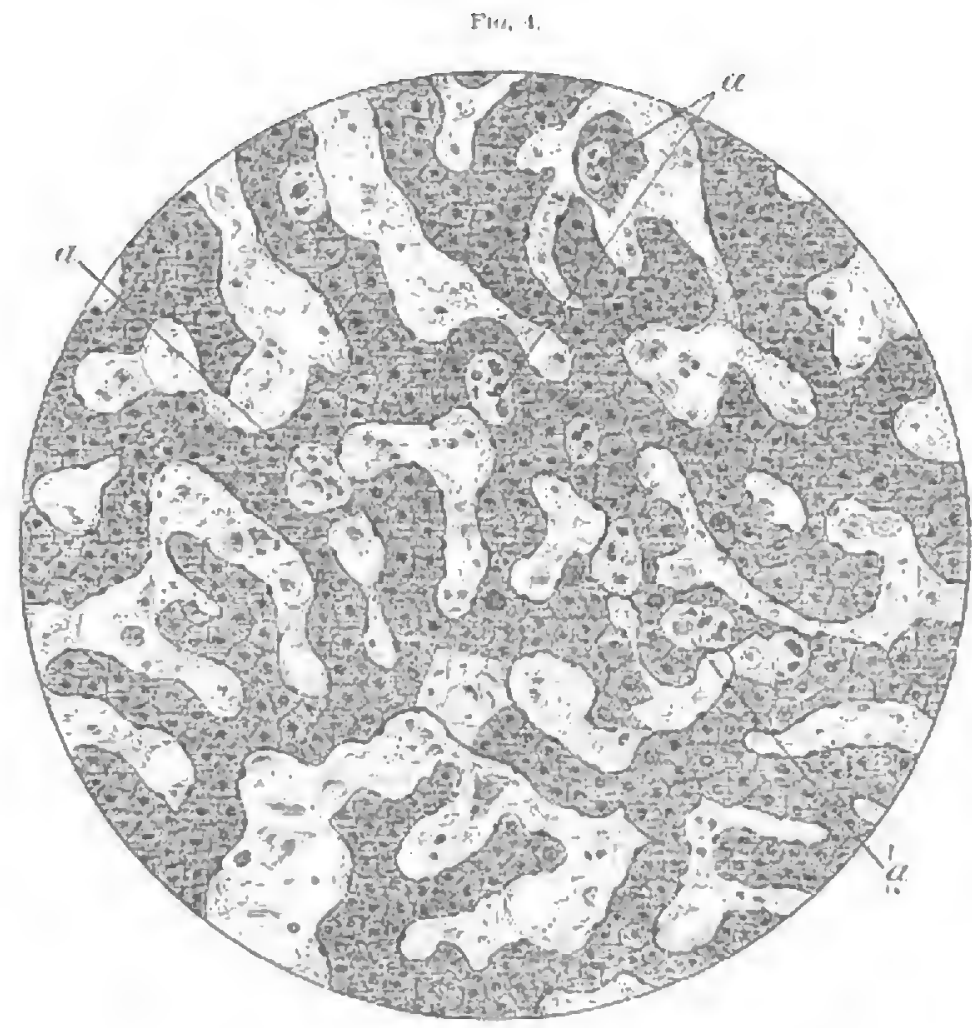

Necrosis of individual cells in human liver, typhoid fever. At $a$ are seen one or more cells which have partially or entirely lost their nuclei and which contain polynuclear leucocytes. In this section the capillaries wereymuch dilated. Camera lucida drawing, Leitz 1/12 immersion objective, No. 3 ocular. Reduced $1 / 3$.

Relation of Bacilli to Areas of Necrosis. We have found characteristic clumps of typhoid bacilli upon section in each of the five cases examined by us; it was generally possible, by careful search, to find one or more colonies in nearly every section, the bacilli lying always within the capillaries. As to the relation existing between these clumps of bacilli and the necrotic areas, we have examined a great many sections from each case, but have only succeeded in finding the bacilli within the areas five times. Four times the colony lay just within the margin of the area; in the remaining instance we observed a capillary 
distended to twice its normal size by a large colony of bacilli, which was surrounded on all sides by necrotic liver-cells, so that the clump of bacilli occupied in this case the centre of the necrosis. We were at first inclined to believe that the finding of the colony of typhoid bacilli within the necrotic area was sufficient reason for assuming that the death of the liver-cells was due to the presence of the bacilli, or rather that the toxalbumin produced by the latter caused the death of the cells in their immediate vicinity. When, however, we had examined very many areas in which no bacilli could be discovered, and when we found colony after colony surrounded by liver-cells, which, to all appearances, were quite healthy, we were reluctantly compelled to leave in abeyance so plausible a theory. With the object, if possible, of coming to a final decision in this matter we made careful serial sections in two of our cases, but prolonged and careful search failed to discover any bacilli within these areas.

Considerable interest must attach to the final disposition of these localized necroses of the liver in those who have recovered from typhoid fever. One is struck with the large number of necrotic cells which must necessarily be removed and whose places must be filled by other cells. Siredey makes the rather surprising statement that during the third week of the disease these nodules no longer appear in the liver; as he believes that they consist largely of lymphoid cells which have been brought to the liver through the portal circulation, he supposes that by the third week they have already re-entered the general circulation. This supposed disappearance of the nodules during the period above mentioned is not borne out by observation, as we have found these lesions in the human liver as early as the second week of the disease, and as late as the seventh week after the attack had begun. Wagner states that they probably entirely disappear, and suggests a restoration of the tissue through a proliferation of the liver cells. While our investigations were being carried on we were so fortunate as to be able to examine microscopically the liver of a patient who had experienced an attack of typhoid fever about twenty-five years prior to death. This was the case of a woman aged about seventy years, who died of carcinoma of the ovary and was autopsied in the pathological laboratory of the Johns Hopkins Hospital. The elinical history of a former attack of typhoid fever was fully supported by finding in the lower ileum several large cicatrized areas, with raised, uneven edges. Microscopical examination of the sections taken from these old cicatrices showed that an ulcerative process had destroyed the mucosa in its entire thickness, and had extended down to the muscular layer. No muscularis mucosæ was to be seen; each ulcer had occupied the greater part of a Peyer's patch, and it was extremely interesting to observe that the follicles of Lieberkühn had been somewhat reproduced, these appearing 
as much atrophied follicles resting directly on the muscular layer. Equal interest attached to the microscopical examinations of the hardened sections of the liver, for, aside from the general atrophy of the liver cells (the patient was quite old), there were to be seen in almost every field from one to three circular, round, ovoid, or irregular-shaped areas of dense connective tissue. These were, as a rule, sharply defined, being situated sometimes near the portal spaces, again around the hepatic vein, and often within the lobules; so that as regards relative position they corresponded to the areas of necroses found in the liver of typhoid fever. Within many of these old areas of connective tissue, bloodvessels and bile-ducts had been reproduced. While it would not be well to attach too much importance to the localized areas of connective tissue found in the liver in this case, we yet consider it of extreme interest to find such an unusual form of cirrhosis in the liver of a patient who had so clearly passed through a former attack of typhoid fever.

Lesions in the Ijivers of Rabbixs Inoculated with Pure Cultures of Typhoid Baciler.-Blackstein ${ }^{2}$ failed to discover any lesions in the liver of rabbits into whose circulation he had injected pure cultures of typhoid bacilli. Legry and Pavone ${ }^{2}$ only found fatty degeneration of the livers cells and of the endothelial cells of the capillaries.

In order to throw further light upon the necrosis found in the human liver, we have injected pure cultures of typhoid bacilli into the mesenteric vein of rabbits, this procedure sufficing to carry the bacilli at once into the hepatic circulation, giving them an opportunity to exert their full effect upon the parenchyma of the liver. The cultures were in plain or one per cent. glucose bouillon, and were from twenty-six hours to twenty days old. The culture which was used for these experiments had been obtained from the spleen of a patient who had died of typhoid fever in the Johns Hopkins Hospital, and had been thoroughly tested as regards its growth on the customary media.

The method of procedure was as follows: The animal having been first etherized, a laparotomy was done under strict antiseptic precautions, and an injection of the culture was then made into one of the larger mesenteric veins by means of a sterilized Koch's syringe; the wound was next carefully closed with silk stitches, and celloidin dressing placed over the line of incision. Although we laparotomized thirteen rabbits, in only ten of these was the injection of the culture into the circulation satisfactorily done. In one of the three unsatisfactory cases the hemorrhage following the withdrawal of the needle was of

1 "Intravenous Inoculation of Rabbits with the Bacillus Coli Communis and the Bacillus Typhi Abdominalis," Johns Hopkins Bulletin, July, 1891, No. 14.

2 " Nuovi Punti di vista nello studio della quistione del potere patogeno del bacillo del Tifo degli anamali da sperimento." Giornale Internacionale delle Scienze Mediche, 1888. 
such amount as to call for the use of a ligature, which was followed by hemorrhagic infarction of the bowel and premature death of the animal. In one case the culture was accidentally injected between the layers of the mesentery, and in one case an attempt was made to inject the culture into one of the smaller branches of the mesenteric artery, which was also followed by hemorrhagic infarction and early death of the animal. We will now give brief protocols of some of our experiments.

Experiment No. 1. May 12, 1891, 10 A.M. Small white rabbit; $0.3 \mathrm{c.cm}$. of a twenty-six hours' old culture of typhoid bacilli in plain bouillon injected into one of the larger mesenteric veins; May 14th, 10 A.M., forty-eight hours after injection, the rabbit was killed. No peritonitis; stomach contained a large quantity of food; moderate amount of fluid feces in small intestine; no enlargement of Peyer's patches or solitary follicles; spleen small, dark red; kidneys normal; liver shows beneath the capsule, on upper and lower surfaces a few roundish or irregular-shaped whitish nodules, 1 to $2 \mathrm{~mm}$. in diameter; there are also to be seen many very minute yellowish dots beneath the capsule and on the cut surface of the organ. Frozen sections show the larger areas to contain coccidia; small areas, however, do not contain these parasites, but are crowded with many fatty granular cells. Coverslips from blood, liver, spleen, and kidneys negative; cultures (gelatin plates) from blood, liver, and spleen show numerous colonies of typboid bacilli; kidney plate negative. Hardened sections of liver stained with methylene blue and eosin show, in addition to the areas containing coccidia, many small foci of cell necrosis. These are situated within the lobules. The liver cells within the area have lost their nuclei; but the beam-work of the cells is as yet unbroken; while in some areas a few polynuclear leucocytes are seen witbin the capillaries; in others the capillaries, especially toward the centre of the areas, contain large numbers of these leucocytes, some of which have even wandered into the dead cells. No bacilli were found on sections.

Experiment No. 2. May 19, 1891, 10 A.M. Small black rabbit; mesenteric vein injected with 0.2 c.cm. of a four days' old culture in plain bouillon. The animal appeared almost overwhelmed by the toxic effects of the injection and died at the end of twenty-three hours. Autopsy made after death; no peritouitis; stomach almost empty; small intestine contains a small quantity of fluid feces; mucous membrane not injected; no enlargement of Peyer's patches or solitary glands; cæcum and large intestine contained a small quantity of hardened fecal matter ; the liver darkly congested and shows characteristic psorosperm nodules; no areas of necrosis apparent to the naked eye, either on the surface or on section; spleen slightly enlarged and dark; kidneys normal ; no cover-slips were made; frozen sections of liver show marked fatty infiltration of the periphery of all the lobules; no necrosis discoverable except those containing coccidia; gelatin plates from liver, spleen, and kidneys, each give numerous colonies of typhoid bacilli; hardened sections of the liver do not show necrotic areas. Although Experiment No. 2 was negative, as far as regards the finding of necrotic areas, it is worth mentioning that a culture of the typhoid bacillus was obtained from the blood in the foregoing cases at the end of forty-eight and twenty-three hours respectively. 
Experiment No. 3. June 24, 1891, 4 P.M. Medium sized rabbit; mesenteric vein injected with a $0.3 \mathrm{cccm}$. of a twenty-six hours' old culture in plain bouillon. Animal killed June 29, 1891, 4 P.M. (at the end of five days). No peritonitis; stomach distended with food ; spleen much enlarged, dark red; many small minute whitish necroses to be seen beneath its capsule; kidneys normal; liver contains a few coccidia nodules; no other areas of necrosis to be observed; frozen sections of the liver appeared to be normal in all respects, except the presence of coccidia above noted; small intestine contains a medium amount of fluid, yellowish feces; mucous membraue of ileum uniformly congested and extending up the gut to the distance of 14 inches above the ileo-creal valve there are to be seen eleven well-marked ulcerations; the largest ulcer involves an entire Peyer's patch and measures 14 by 21 millimetres; the others are small roundish oval ulcers and involve the solitary follicles; all of them contain a central slough, the necrotic process extending in several down to the peritoneal coat of the bowel; all have overhanging edges and show a distinct margin of congestion ; large intestine normal; the mesenteric glands distinctly enlarged, and several show upon the surface, and upon section, small yellowish areas of necrosis ; cultures from right ventricle, liver, spleen, mesenteric glands, and kidneys; the plates from liver and spleen show numerous colonies of typhoid bacillus, while those from the blood, mesenteric glands, and kindneys give a few colonies of staphylococcus citreus; hardened sections of the mesenteric glands and of the spleen give characteristic caseous areas of tuberculosis; numerous tubercle bacilli found on stained sections; hardened sections of liver normal; sections of the intestinal ulcers show, microscopically, a central necrosis extending down to and in rolving the peritoneal coat; this necrosis, in each instance, is densely surrounded by an area of polynuclear leucocytes; outside of these were seen a few epithelioid cells in the submucosa ; repeated examinations of stained sections of the ulcers failed to discover any tubercle bacilli whatever. With regard to Experiment No. 3, although the microscopical examination proved that the mesenteric glands were tuberculous, the latter condition was definitely excluded from the process, as seen in the intestinal ulcers. The absence of tubercle bacilli in these, the presence of a central area of necrosis surrounded by crowds of polynuclear leucocytes, the involvement of Peyer's patches and solitary glands in the ulcerative process, would we think, bear out the latter statement.

Experiment No. 6. July 2, 1891, 10 A.M. Medium-sized rabbit 0.2 c.cm. of a twenty-four hours' culture in 1 per cent. sugar bouillon injected into the mesenteric vein. Animal killed July $7 \mathrm{th}, 5$ P.M. (three days, seven hours) ; stomach distended with food; small and large intestine normal ; spleen not enlarged; kidneys normal ; no necrotic areas found in the liver either on frozen or hardened sections; cultures from the blood negative; those from the bile, liver, and spleen give numerous colonies of typhoid bacilli.

Experiment No. 7. July 24, 1891, 4 P.M. Large black rabbit; 0.5 c.cm. of a thirty-six hours' culture in 1 per cent. sugar bouillon injected into mesenteric vein; after recovery from the anesthetic the animal showed symptoms of acute toxæmia; remained lying on its side with marked tremor of extremities for more than twelve hours; this passed off during the second day; July $29 \mathrm{th}, 4$ P.M. (five days) animal killed; no peritonitis; stomach contains moderate amount of food; small and 
large intestine normal; spleen much enlarged, estimated to be three times its normal size, dark purplish-red, firm; kidneys normal; liver presents within its parenchyma, immediately beneath the walls of the gall-bladder, numerous yellowish, white, roundish necroses; walls of gall-bladder much thickened, bile pale, watery, non-viscid, and contains many minute yellowish floating particles; hanging drop made from bile shows a large number of highly motile rods, corresponding in size to the typhoid bacillus; cover-slips from the various organs negative; gelatin plates from bile, spleen, and liver give numerous typhoid colonies; plates from the blood and kidneys negative; microscopical ex-

Fig. 5 .

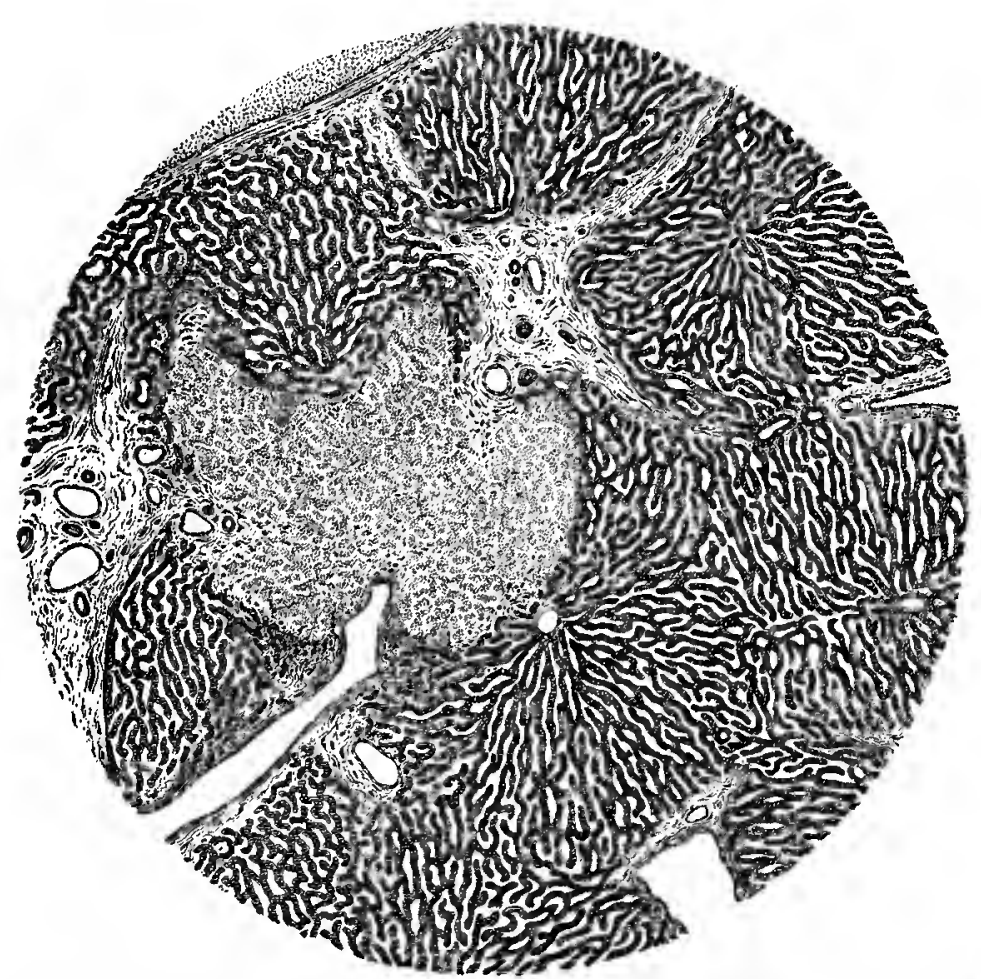

Rabbit's liver, experimental typhoid fever. A necrosis involving parts of three lobules; animal killed on the seventh day after inocnlation into mesenteric vein of a pure culture of typhoid baeilli. Camera lueída drawing, Bausch \& Lomb objectíve 2/3, Leitz ocular No. 4. Reduced $1 / 3$.

amination of hardened sections of liver extending through the wall of the gall-bladder show distinct necrosis of the mucous membrane of the gall-bladder, with loss of substance, and in the parenchyma of the liver proper many small and large necroses involving the liver cells; these areas stained brightly with eosin; within the capillaries of several of the areas there are seen many polynuclear leucocytes; one such necrosis occupies almost an entire lobule. 
Experiment No. 8. August 14, 1891, 9.30 A.M. Large white rabbit; mesenteric vein injected with $0.4 \mathrm{c.cm}$. of a twenty days' old culture in 1 per cent. plain bouillon; August 21, 1891, 9.30 A.M. (seven days) animal killed; no peritonitis; stomach, large and small intestine presented nothing worthy of remark; spleen slightly enlarged, dark red; kidneys nornial; liver presents, beneath its capsule and on section, numerous minute, yellowish-white necroses; bile green and viscid; cultures from blood, bile, liver, kidneys, and spleen positive; frozen sections of liver show many necroses, consisting largely of fatty granular liver cells; hardened sections of the liver show necroses, both large and small, resembling in all respects those found in the human liver of typhoid fever.

Experiment No. 11. August 31, 1891,4 P.M. Large rabbit; injection into mesenteric vein 0.5 c.c. of twenty-four-hours'old culture in plain bouillon; no symptoms of acute toxæmia. September 4th, 10 A.M. (four days after injection), animal killed. No peritonitis; stomach and intestines normal; spleen not enlarged; kidneys normal; liver, numerous very small, round, yellowish necroses under capsule on the upper and lower surface and on section; bile, green, viscid ; cover-slips from the organs negative; gelatin plates from blood, liver, spleen, and kidneys negative; plates from bile contained numerous typhoid colonies; frozen sections fron liver showed diffuse fatty degeneration of liver cells and many small necrotic foci; hardened sections gave most characteristic foci of cell death, and there was seen within a branch of the portal vein an extensive thrombus.

Experiment No. 12. August 31, 1891, 5 P.M. Large rabbit; 0.5 c.c. plain bouillon culture, twenty-four hours old, injected into mesenteric vein; killed September 13, 1891 (fourteen days after injection); no peritonitis ; spleen dark red and much enlarged; stomach and intestines normal ; kidneys very pale on section; striation well marked; liver, numerous minute, sharply defined, yellowish-white areas under capsule and scattered through the liver parenchyma; frozen sections show diffuse, fatty degeneration of liver cells, and well-defined areas of necrosis; frozen sections of kidney show marked fatty degeneration of the epithelium of both the convoluted and straight tubes; cultures from blood and kidney negative; liver, spleen, and bile plates give numerous typhoid colonies; hardened sections of liver show many characteristic areas of cell necrosis.

Of the ten rabbits successfully injected into the mesenteric vein with pure cultures of typhoid bacillus, five gave positive results-that is, following this injection, at intervals varying from two to fourteen days, the animals were killed, and upon examination of the liver there were discovered well-defined, localized areas of cell necrosis.

Taken in connection with the localized lesions found in the liver of typhoid fever in man the changes brought about in the rabbit's liver are particularly instructive; for, although in the former it could not be positively determined just how much the presence of the bacillus coli communis contributed to the production of these necroses, we have obtained, in the latter, lesions in all respects identical with those found in the human liver by the injection of pure cultures of the typhoid bacil- 
lus, and where any action of the colon bacillus could be certainly excluded. The inference would appear to be a legitimate one that the typhoid bacillus is quite capable of producing the areas of necrosis which are so marked a feature in the human liver.

As in the human liver, so likewise in the rabbit's liver we find the essential lesion to be, first, a necrosis of the cells proper of the organ in localized areas, varying in size from a few cells up to an entire lobule, followed by the accumulation of polynuclear leucocytes within the capillaries of the area and their subsequent migration into the dead cells.

With regard to the relation of the bacilli to the experimentally-produced areas of necrosis, we have not succeeded in finding any bacilli present in the areas; nor have we found colonies of the bacilli on section of the rabbit's liver. Our experience has in this accorded with other workers in this line. The explanation for the failure to find the bacilli on section is most probably due to the fact that the tissues were subjected to the influence of hardening agents immediately after the animals had been killed. As is well known, Fränkel and Simmonds have shown that, by keeping the spleen and liver of rabbits which have been inoculated with typhoid bacilli for periods varying from twenty-four hours to three or more days, especially at thermostat temperature, the bacilli rapidly multiply, so that, whereas, immediately after the death of the rabbit it was with much difficulty that they could be found, at a later time numerous colonies were to be seen on sections of both liver and spleen. Bearing this in mind, it may be allowable to suppose that many of the colonies of typhoid bacilli found on section in the human liver have developed between the death of the patient and the time of subjecting the tissues to preservative agents. This may account for the fact that so many of the colonies are seen to be surrounded by apparently quite healthy liver cells.

To briefly summarize, then, the results of our study of the lesions found in the human liver following upon an attack of typhoid fever, we believe that we may draw the following conclusions:

1. That the term "lymphoid nodule," by which these localized lesions of the liver in typhoid fever have been heretofore generally designated, is an improper one, since it expresses an erroneous idea as to the origin of these peculiar formations.

2. That these so-called lymphomata are not composed of lymphoid cells, as the term would imply, which have wandered in from the portal vessels, but that, on the contrary, these focci represent well-defined areas of cell-death.

3. That in the earlier stages of the necrosis the nuclei which are found in such abundance in these areas are not the nuclei of lymphoid cells (Orth, Hoffman, Siredey), nor do they arise from the multiplication of the nuclei of the hepatic cells (Wagner, Hoffman), but owe their origin 
in small part to the disintegration of the nuclei of the liver cells involved, and in greater part to the presence of polynuclear leucocytes which have wandered into the necrotic area.

4. That at a later stage of the process, when the liver cells have become quite broken down into granular detritus, the numerous small, round, and sometimes spindle-shaped nuclei which are observed along the margins of the area, or seen to have penetrated into its centre, are those derived from the connective tissue stroma of the organ (Wagner, Handford).

5. That thus it is probable that the areas of necrosis are replaced by well-defined areas of localized connective tissue.

6. That necrotic areas, resembling in all respects those found in the human liver in typhoid fever, can be reproduced experimentally in the rabbit's liver by the injection into the mesenteric vein of a pure culture of the typhoid bacillus.

7. That although these areas of necrosis in the liver owe their origin to the action of the typhoid bacillus, it has not been possible to more definitely determine in what way this cell death is brought about-that is to say, whether it is due to the immediate presence of the bacilli within the areas of necrosis, or is caused by the action of the so-called toxalbumins which are assumed to be present in the general circulation. It would seem reasonable to suppose that the latter explanation is the more probable, since it is possible to produce well-defined areas of necrosis in the liver of guinea-pigs by the injection of toxalbumins alone, as has been done by Welch and Flexner ${ }^{1}$ in diphtheria, and more recently by Flexner ${ }^{2}$ by means of minute injections of ricin and abrin.

In conclusion, we desire to express our warmest thanks to Professor Welch, of the Johns Hopkins University, and Professor Councilman, now of Harvard University, for the valuable suggestions made from time to time during the progress of this investigation, and to state that the success attending the experimental work was largely due to their kind advice and assistance.

1 Johns Hopkins Hospital Bulletin, 1892, vo1. iii. No. 20.

2 "The Pathologic Changes Caused by Certain So-called Toxalbumins," Medical News, August 4, 1894. 